\title{
Yale Food Addiction Scale: Examining the Psychometric Properties of the French Version among Individuals with Severe Obesity Awaiting Bariatric Surgery
}

\author{
Anne-Sophie Ouellette1, Christopher Rodrigue1, Simone Lemieux ${ }^{2,3}$, André Tchernof ${ }^{2,4}$, \\ Laurent Biertho ${ }^{4,5}$, Catherine Bégin1,3 \\ ${ }^{1}$ School of Psychology, Laval University, Québec, Canada \\ ${ }^{2}$ School of Nutrition, Laval University, Québec, Canada \\ ${ }^{3}$ Institute of Nutrition and Functional Foods, Laval University, Québec, Canada \\ ${ }^{4}$ Quebec Heart and Lung Institute, Québec, Canada \\ ${ }^{5}$ Department of Surgery, Laval University, Québec, Canada \\ Email: catherine.begin@psy.ulaval.ca
}

How to cite this paper: Ouellette, A.-S., Rodrigue, C., Lemieux, S., Tchernof, A., Biertho, L., \& Bégin, C. (2017). Yale Food Addiction Scale: Examining the Psychometric Properties of the French Version among Individuals with Severe Obesity Awaiting Bariatric Surgery. Psychology, 8, 2547-2561.

https://doi.org/10.4236/psych.2017.814161

Received: November 1, 2017

Accepted: December 24, 2017

Published: December 27, 2017

Copyright $\odot 2017$ by authors and Scientific Research Publishing Inc. This work is licensed under the Creative Commons Attribution International License (CC BY 4.0).

http://creativecommons.org/licenses/by/4.0/ (c) () Open Access

\begin{abstract}
The French version of the Yale Food Addiction Scale (YFAS), used to evaluate food addiction symptomatology, has only been validated among the general population. The aim of this study was thus to explore the psychometric properties (factor structure, internal consistency, convergent and divergent validity) of the French version of the YFAS in a clinical sample, namely individuals suffering from severe obesity and awaiting bariatric surgery. Participants $(\mathrm{N}=$ 146; mean BMI $=48.29 \mathrm{~kg} / \mathrm{m}^{2}$ ) were recruited at the Quebec Heart and Lung Institute (Canada) during their pre-operative visit. They were asked to complete questionnaires, including the YFAS. Factorial and correlational analyses were performed. Some items had to be removed from the factorial analysis due to a lack of variability (\#4, \#10,\#11,\#12, and \#22) and low factor loading (\#24). The analysis conducted on the remaining 16 items revealed a one-factor structure, with factor loadings higher than .30 and excellent internal consistency $(\alpha=.92)$. The present findings are consistent with previous validation studies of samples presenting obesity and support the use of a 16-item version of the French YFAS among bariatric candidates. However, the need for further investigation remains important in order to better assess the stability of the instrument when used in clinical samples.
\end{abstract}

\section{Keywords}

Food addiction, Yale Food Addiction Scale, Bariatric Surgery, Obesity,

Psychometric Properties, Validation 


\section{Introduction}

The growing interest of many researchers in the field of obesity has recently led to a rapidly expanding body of literature regarding the concept of food addiction (FA). Briefly stated, the concept of FA was developed based on similarities between the effect of sweet and high-fat foods and psychoactive substances, observed in animal and neuroimaging studies (Davis \& Carter, 2009). Following the DSM-IV-TR substance dependence diagnostic criteria (American Psychiatric Association, 2000), the Yale Food Addiction Scale (YFAS) was developed as a self-reported questionnaire designed to operationalize FA (Gearhardt, Corbin, \& Brownell, 2009). Since its development, the YFAS has remained the only questionnaire available to investigate the concept of FA.

The YFAS consists of 25 items assessing the seven diagnostic criteria of substance dependence as well as the associated functional impairment/clinically significant distress and presents two scoring options: one based on the fulfilled items and another based on the fulfilled criteria. Gearhardt and colleagues (2009) first proceeded to the validation of the YFAS in a sample of undergraduate students. Analyses examining the item-based scoring option showed a one-factor structure as well as good internal consistency $(\alpha=.86)$, when removing item 24 . This item, which assesses failed attempts to reduce highly palatable food consumption, was considered problematic in light of low factor loading and poor correlations with the remaining items. Similarly, analyses examining the criteria-based scoring option showed a one-factor structure and satisfying internal consistency $(\alpha=.75)$. Correlational analyses also suggested good convergent validity with measures of related constructs (eating pathology; $r$ ranging from .46 to .61 ) and divergent validity with measures of related but independent constructs (alcohol consumption and impulsivity; $r$ ranging from -.03 to .35 ) for both scoring options. Regarding divergent validity, an absence of association has also been noted between FA and dietary restraint (Gearhardt, White, Masheb, Morgan, Crosby, \& Grilo, 2012; Gearhardt, White, Masheb, \& Grilo, 2013; Meule, Heckel, Jurowich, Vogele, \& Kubler, 2014).

The YFAS has also been validated among individuals from the general population (Brunault, Ballon, Gaillard, Réveillère, \& Courtois, 2014), individuals presenting obesity (Davis, Curtis, Levitan, Carter, Kaplan, \& Kennedy, 2011), individuals suffering from various eating disorders (Gearhardt et al., 2012; Granero et al., 2014), individuals seeking weight-loss treatments (Innamorati et al., 2015; Nantha, Patah, \& Pillai, 2016), and individuals awaiting bariatric surgery (Clark \& Saules, 2013; Meule, Heckel, \& Kubler, 2012). A closer look at these validation studies has shown that comparable psychometric properties were found when the YFAS was examined among similar samples according to BMI. For example, results from the general population (mean BMI around $23.00 \mathrm{~kg} / \mathrm{m}^{2}$ ) have shown a one-factor structure, when item 24 was removed from the analyses (Gearhardt et al., 2009; Brunault et al., 2014; Granero et al., 2014; Torres et al., 2017). However, results from samples presenting a higher mean BMI (around $40.00 \mathrm{~kg} / \mathrm{m}^{2}$ ) revealed that some additional items were problematic and had to 
be removed in order to observe a stable one-factor structure (Innamorati et al., 2015; Nantha et al., 2016; Meule et al., 2012). In sum, these results highlight the fact that the YFAS may behave differently depending on the recruited sample.

Furthermore, the original version of the instrument has been translated and adapted in German, Spanish, French, Italian, Chinese, Malay, and Portuguese (Meule, Vogele, \& Kubler, 2012; Granero et al., 2014; Brunault et al., 2014; Innamorati et al., 2015; Chen, Tang, Guo, Liu \& Xiao, 2015; Nantha et al., 2016; Torres et al., 2017). Regarding the French version more specifically, it was adapted by researchers in France (Brunault et al., 2014) and validated among individuals from the general population. It is the only validation study that has explored an alternative two-factor structure. According to the authors, the first factor appeared to represent FA symptomatology, while the second factor composed of items $10,11,15,16,22$, and 25 appeared to represent individuals' insight pertaining to their FA symptoms. While the French version has shown good psychometric properties in a non-clinical sample, it has not yet been validated among clinical samples. In light of the sample-dependent differences underlined above and as mentioned by the authors of the original YFAS (Gearhardt et al., 2009) and its French version (Brunault et al., 2014), validation studies in both non-clinical and clinical samples are essential in order to fully use the YFAS and explore FA among various groups. Moreover, the necessity for cross-cultural adaptations when a self-reported instrument is used across different countries and cultures has previously been highlighted (Beaton, Bombardier, Guillemin, \& Ferraz, 2000).

The aim of the present study was to examine the psychometric properties of the French version of the YFAS in a clinical sample. Bariatric candidates were chosen considering that these individuals suffering from severe obesity present greater risks for physical and psychological complications (World Health Organization, 2017) and that FA prevalence rates as high as 54\% have been found in such clinical sample (Clark \& Saules, 2013). The need for a valid instrument to assess FA in this sample was therefore deemed essential. It was hypothesized that a one-factor solution would be observed, despite some problematic items. It was also expected to find good internal consistency as well as good convergent validity (strong correlations of the YFAS with binge eating and food cravings) and good divergent validity (mild correlation of the YFAS with impulsivity and near-zero correlations of the YFAS with dietary restraint and addictive tendencies towards alcohol and drugs).

\section{Methods}

\subsection{Participants and Procedure}

The present study was approved by the Research Ethics Committee of the Quebec Heart and Lung Institute. Participants were recruited through the activities of the Research Chair in Bariatric and Metabolic Surgery at the Heart and Lung Institute Research Centre in Quebec City. They were considered eligible for the study if they were aged between 18 and 50 years old, presented a BMI of 35.00 
$\mathrm{kg} / \mathrm{m}^{2}$ or above, and met the necessary requirements for bariatric surgery. After giving their informed consent, they were handed a booklet of questionnaires. Weight and height information were obtained from the participants' medical files. The final sample comprised 146 individuals (112 women and 34 men), who presented a mean age of 39.8 years old $(S D=7.1)$ and a mean BMI of 48.29 $\mathrm{kg} / \mathrm{m}^{2}(S D=6.24)$. The vast majority of the participants were White/Caucasian $(98 \%)$. Most of them had completed a post-secondary degree (60\%) and reported working full time (79\%).

\subsection{Measures}

\subsubsection{FA}

The YFAS (Gearhardt et al., 2009) is an instrument used to assess behaviors related to FA in the last 12 months. It is a self-reported measure and comprises 25 items, among which 20 pertain to the seven DSM-IV-TR diagnostic criteria for substance dependence (American Psychiatric Association, 2000), two assess functional impairment/clinically significant distress, and three provide clarification for subsequent items (primer items). Most items contained in the YFAS are answered on a Likert scale, ranging from zero (never) to four (more than four times a week or every day). The remaining items are dichotomous and answered by yes or no. As shown in Table 1, the 22 active YFAS items are transformed for scoring (zero if not endorsed, one if endorsed) according to a pre-established chart (Meule \& Gearhardt, 2014). A criterion is considered fulfilled when the respondent endorses at least one item pertaining to the criterion. Two scoring options are available: the first is in the form of a total symptom count and is obtained by summing up the fulfilled criteria (except the functional impairment/clinically significant distress criterion), ranging from zero to seven and indicating FA severity, and the second is in the form of a "FA diagnosis", indicating the presence of such diagnosis if three or more criteria are fulfilled in addition to the endorsement of functional impairment/clinically significant distress.

\subsubsection{Impulsivity}

The Barratt Impulsiveness Scale-Brief (BIS-Brief) (Steinberg, Sharp, Stanford, \& Tharp, 2013) is the brief version of the Barratt Impulsiveness Scale (Barratt, 1959). It is composed of eight of the original items, namely items $1,2,5,8,9,12$, 14, and 19. Respondents are instructed to answer on a four-point Likert scale, ranging from one (never/rarely) to four (often/always), depending on the frequency of occurrence of the different behaviors presented. A total score is obtained by adding up all items: higher total scores are associated with higher levels of impulsivity. In the context of the present study, the internal consistency of the BIS-Brief was satisfying $(\alpha=.70)$.

\subsubsection{Binge Eating}

The Binge Eating Scale (BES) (Gormally, Black, Daston, \& Rardin, 1982) comprises 16 items and is used to measure symptoms related to behavioral as well as 
Table 1. Food addiction criteria and associated items from the Yale Food Addiction Scale.

\begin{tabular}{|c|c|c|c|}
\hline \multirow[t]{2}{*}{ Criteria } & \multirow[t]{2}{*}{ Associated Items } & \multicolumn{2}{|c|}{ Scoring } \\
\hline & & 0 & 1 \\
\hline & $\begin{array}{l}\text { 1. I find that when I start eating certain foods, I end up eating much more than } \\
\text { planned. }\end{array}$ & $0-3$ & 4 \\
\hline \multirow[t]{3}{*}{$\begin{array}{l}\text { Substance taken in larger amounts } \\
\text { and for longer periods than intended }\end{array}$} & $\begin{array}{l}\text { 2. I find myself continuing to consume certain foods even though I am no longer } \\
\text { hungry. }\end{array}$ & $0-3$ & 4 \\
\hline & 3. I eat to the point where I feel physically ill. & $0-2$ & $3-4$ \\
\hline & 5. I spend a lot of time feeling sluggish or fatigued from overeating. & $0-2$ & $3-4$ \\
\hline \multirow{3}{*}{$\begin{array}{l}\text { Much time/activity to obtain, use, } \\
\text { recover }\end{array}$} & 6. I find myself constantly eating certain foods throughout the day. & $0-3$ & 4 \\
\hline & $\begin{array}{l}\text { 7. I find that when certain foods are not available, I will go out of my way to obtain } \\
\text { them. For example, I will drive to the store to purchase certain food options available } \\
\text { to me at home. }\end{array}$ & $0-2$ & $3-4$ \\
\hline & $\begin{array}{l}\text { 8. There have been times when I consumed certain foods so often or in such large } \\
\text { quantities that I started to eat food instead of working, spending time with my family } \\
\text { or friends, or engaging in other important activities or recreational activities I enjoy. }\end{array}$ & $0-1$ & $2-4$ \\
\hline \multirow[t]{4}{*}{$\begin{array}{l}\text { Important social, occupational, or } \\
\text { recreational activities given up or } \\
\text { reduced }\end{array}$} & $\begin{array}{l}\text { 9. There have been times when I consumed certain foods so often or in such large } \\
\text { quantities that I spent time dealing with negative feelings from overeating instead of } \\
\text { working, spending time with my family or friends, or engaging in other important } \\
\text { activities or recreational activities I enjoy. }\end{array}$ & $0-2$ & $3-4$ \\
\hline & $\begin{array}{l}\text { 10. There have been times when I avoided professional or social situations where } \\
\text { certain foods were available, because I was afraid I would overeat. }\end{array}$ & $0-1$ & $2-4$ \\
\hline & $\begin{array}{l}\text { 11. There have been times when I avoided professional or social situations because I } \\
\text { was not able to consume certain foods there. }\end{array}$ & $0-1$ & $2-4$ \\
\hline & $\begin{array}{l}\text { 12. I have had withdrawal symptoms such as agitation, anxiety, or other physical } \\
\text { symptoms when I cut down or stopped eating certain foods. }\end{array}$ & $0-2$ & $3-4$ \\
\hline \multirow[t]{2}{*}{ Withdrawal symptoms } & $\begin{array}{l}\text { 13. I have consumed certain foods to prevent feelings of anxiety, agitation, or other } \\
\text { physical symptoms that were developing. }\end{array}$ & $0-2$ & $3-4$ \\
\hline & $\begin{array}{l}\text { 14. I have found that I have elevated desire for or urges when I cut down or stop } \\
\text { eating them. }\end{array}$ & $0-2$ & $3-4$ \\
\hline \multirow{2}{*}{$\begin{array}{l}\text { Use causes clinically significant } \\
\text { impairment or distress }\end{array}$} & 15. My behavior with respect to food and eating causes significant distress. & $0-2$ & $3-4$ \\
\hline & $\begin{array}{l}\text { 16. I experience significant problems in my ability to function effectively because of } \\
\text { food and eating. }\end{array}$ & $0-2$ & $3-4$ \\
\hline \multirow{4}{*}{$\begin{array}{l}\text { Use continues despite knowledge of } \\
\text { adverse consequences } \\
\text { Tolerance }\end{array}$} & $\begin{array}{l}\text { 19. I kept consuming the same types of food or the same amount of food even though } \\
\text { I was having emotional and/or physical problems. }\end{array}$ & no & yes \\
\hline & $\begin{array}{l}\text { 20. Over time, I have found that I need to eat more and more to get the feeling I want, } \\
\text { such as reduced negative emotions or increased pleasure. }\end{array}$ & no & yes \\
\hline & $\begin{array}{l}\text { 21. I have found that eating the same amount of food does not reduce my negative } \\
\text { emotions or increase pleasurable feelings the way it used to. }\end{array}$ & no & yes \\
\hline & $\begin{array}{l}\text { 4. Not eating certain types of food or cutting down on certain types of food is } \\
\text { something I worry about. }\end{array}$ & no & yes \\
\hline \multirow{3}{*}{$\begin{array}{l}\text { Persistent desire or repeated unsuc- } \\
\text { cessful attempts to quit }\end{array}$} & 22. I want to cut down or stop eating certain kinds of food. & no & yes \\
\hline & 24. I have been successful at cutting down or not eating these kinds of food. & no & yes \\
\hline & $\begin{array}{l}\text { 25. How many times in the past year did you try to cut down or stop eating certain } \\
\text { foods altogether? }\end{array}$ & $0-3$ & 4 \\
\hline
\end{tabular}


cognitive and emotional manifestations of binge eating episodes. For each item, the respondent is asked to choose, among four statements, the one that best represents his or her situation. Each item is allocated weights representing severity (varying between zero and three), which are subsequently summed up. Higher total scores are associated with more severe binge eating pathology. Internal consistency for the BES in the present sample was good $(\alpha=.85)$.

\subsubsection{Food Cravings}

The Food Craving Questionnaire-Trait (FCQ-T) (Cepeda-Benito, Gleaves, Williams, \& Erath, 2000) is a self-reported questionnaire composed of 37 items and designed to evaluate nine dimensions of food cravings. In the trait version of the FCQ, participants have to indicate how often each statement "would be true for them in general" using a six-point Likert scale, ranging from never to always. Only the FCQ-T total score was used considering that all subscales were strongly correlated in the present sample ( $r$ ranging from .52 to .84 , all $p<.001$ ). Relatedly, the overall internal consistency was excellent $(\alpha=.98)$.

\subsubsection{Restraint Eating}

The Eating Disorder Examination (EDE) (Cooper \& Fairburn, 1987) was used in order to measure restraint eating. The EDE is a semi-structured interview and consists of 62 items evaluating eating-related behaviors from the past four weeks. Only the question pertaining to dietary restraint "Have you been deliberately trying to limit the amount of food you eat to influence your shape or weight (whether or not you have succeeded)" was of interest in the context of the present study. Answers were given on a seven-point Likert scale, ranging from zero (never) to six (everyday).

\subsubsection{Addictive Tendencies towards Alcohol and Drugs}

The Shorter PROMIS Questionnaire (SPQ) (Christo, Jones, Haylett, Stephenson, Lefever, \& Lefever, 2003) is a self-reported questionnaire divided in 16 subscales, each evaluating addictive tendencies in regards to various substances or activities. In consistence with previous validation studies, the subscales related to alcohol consumption and recreational drug use were specifically considered in the present study. Both subscales are made of ten items where respondents are asked to indicate, on a six-point Likert scale, the extent to which the items apply to them (from "not like me", scored zero, to "like me", scored five). In the present sample, both the alcohol and the drug subscales showed good internal consistency ( $\alpha=.87$ and $\alpha=.89$, respectively).

\subsection{Data Analytic Plan}

The present analyses were based on the procedures described by Gearhardt and colleagues (2009) and Brunault and colleagues (2014) in their validation studies. In order to examine the factorial structure of the instrument in its severity form (symptom count scoring option), an exploratory factor analysis based on the 22 transformed items (excluding the primer items 17, 18, and 23) was conducted. 
For the diagnosis form of the instrument (diagnosis scoring option), an exploratory factor analysis was also conducted based on the seven diagnostic criteria as well as on the functional impairment/clinically significant distress criterion. The final number of factors to extract was confirmed by a scree test procedure based on eigenvalues (Cattell, 1966). Internal consistency was established using the ordinal alpha coefficient for dichotomous data (Zumbo, Gadermann, \& Zeisser, 2007). MPlus Statistical Package was used considering the dichotomous nature of the data and a robust weighted least squares (WLSMV) estimator with a polychoric correlation matrix coefficient was chosen for factor extraction (B Muthén, SHC du Toit, \& D Spisic, unpublished data). For both the severity and the diagnosis forms of the YFAS, construct validity was assessed using correlational analyses. Pearson's $r$ was used for all variables, except for the alcohol and the drug subscales of the SPQ, for which Spearman's $\rho$ was used because of the variables' abnormal distributions. Correlational analyses were conducted using Statistical Package for Social Sciences (SPSS).

\section{Results}

\subsection{Factorial Structure of the YFAS}

Originally based on the 22 items of the French YFAS, the exploratory factor analysis for the symptom count scoring option required the removal of five items, namely items $4,10,11,12$, and 22 , due to an absence of variability. In fact, MPlus warned that one of the response options for each of these items was poorly represented within the sample: for instance, item 22 was endorsed by many participants (94\%), while items $4,10,11$, and 12 were endorsed by few participants (endorsement rates ranging from $1 \%$ to $10 \%$ ). Furthermore, the exploratory factor analysis conducted on the remaining 17 YFAS items showed that item 24 had low factor loading (0.271), thus suggesting its removal. A final exploratory factor analysis, conducted on the remaining 16 YFAS items, revealed the presence of five factors with eigenvalues higher than $1.00(7.28,2.21,1.34$, $1.19,1.01)$. However, the examination of the scree plot (Figure 1) suggested that a one-factor solution would be most appropriate, accounting for $47 \%$ of the explained variance and yielding excellent internal consistency $(\alpha=.92)$ (Table 2). When using the symptom count scoring option of the 22 YFAS items, it was found that participants endorsed an average of $2.66(S D=1.65)$ symptoms, in comparison to $2.16(S D=1.78)$ symptoms when using the remaining 16 YFAS items.

Regarding the diagnosis scoring option, the criterion "Persistent desire or repeated unsuccessful attempts to quit" was vastly endorsed (97\%) and thus could not be considered in the exploratory factor analysis. The exploratory factor analysis was then conducted on the remaining criteria, namely the six diagnostic criteria and the functional impairment/clinically significant distress criterion, and suggested a one-factor solution with only one eigenvalue higher than 1.00 (4.01). Under this one-factor solution, accounting for 53\% of the explained 
Table 2. Descriptive statistics, factor loading, and communality for each Yale Food Addiction Scale item.

\begin{tabular}{|c|c|c|c|}
\hline YFAS items & $M(S D)$ & Factor loadings & Communalities \\
\hline 1 & $0.14(0.35)$ & .73 & .53 \\
\hline 2 & $0.12(0.33)$ & .72 & .53 \\
\hline 3 & $0.14(0.35)$ & .85 & .72 \\
\hline 4 & $0.10(0.30)$ & ----- & ----- \\
\hline 5 & $0.20(0.40)$ & .70 & .49 \\
\hline 6 & $0.08(0.26)$ & .74 & .54 \\
\hline 7 & $0.12(0.33)$ & .75 & .56 \\
\hline 8 & $0.05(0.21)$ & .82 & .67 \\
\hline 9 & $0.05(0.21)$ & .82 & .67 \\
\hline 10 & $0.01(0.08)$ & ------ & ------ \\
\hline 11 & $0.01(0.08)$ & ----- & ------ \\
\hline 12 & $0.03(0.16)$ & ----- & ------ \\
\hline 13 & $0.06(0.24)$ & .59 & .35 \\
\hline 14 & $0.18(0.39)$ & .82 & .67 \\
\hline 15 & $0.12(0.33)$ & .62 & .38 \\
\hline 16 & $0.11(0.31)$ & .59 & .36 \\
\hline 19 & $0.50(0.50)$ & .51 & .26 \\
\hline 20 & $0.19(0.40)$ & .67 & .45 \\
\hline 21 & $0.29(0.45)$ & .54 & .29 \\
\hline 22 & $0.94(0.24)$ & ------ & ----- \\
\hline 24 & $0.32(0.47)$ & ----- & ----- \\
\hline 25 & $0.49(0.50)$ & .35 & .12 \\
\hline
\end{tabular}

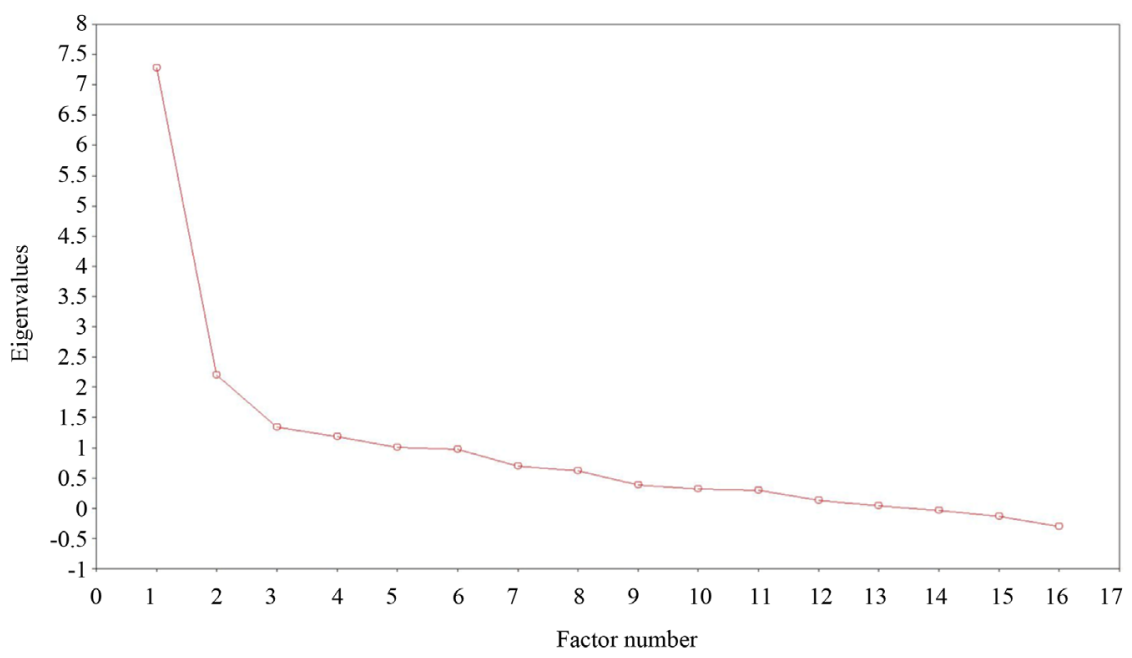

Figure 1. Scree plot and eigenvalues for the symptom count scoring option of the French Yale Food Addiction Scale. 
variance, all factor loadings were higher than .50 and internal consistency was good $(\alpha=.88)$ (Table 3$)$. When using the diagnosis scoring option of the integral YFAS, it was found that $18 \%$ of participants suffered from FA, in comparison to $14 \%$ when using the remaining criteria.

\subsection{Construct Validity of the YFAS}

The following correlational analyses were conducted using the 16-item version of the YFAS (symptom count scoring option) as well as the six criteria accompanied by the functional impairment/clinically significant distress criterion (diagnosis scoring option). In regards to convergent validity, correlational analyses revealed strong statistically significant correlations between the YFAS symptom count and scores on the BES $(p<001)$ and the FCQ-T $(p<001)$. Similar results were observed when the diagnosis scoring option of the instrument was used (BES $p<001$; FCQ-T $p<001$ ) (Table 4). In regards to divergent validity, the correlations between the YFAS symptom count and scores on the SPQ alcohol and drug subscales were non significant $(p=.803 ; p=.179$, respectively), while correlations between the YFAS symptom count and scores on the BIS-Brief and the EDE dietary restraint subscale were mild but significant ( $p=.004 ; p=.019$, respectively). Results regarding the YFAS diagnosis scoring option were slightly different: non-significant correlations were observed between the YFAS diagnosis and scores on the SPQ alcohol subscale $(p=.959)$, the SPQ drug subscale ( $p$ $=.101)$, the BIS-Brief $(p=.110)$, and the EDE dietary restraint subscale ( $p$ $=.215)($ Table 4$)$.

\section{Discussion}

Results from the exploratory factor analyses revealed a one-factor solution. The alternative two-factor solution, as found by Brunault and colleagues (2014), could not be observed in the present study. Both the nature of the samples and

Table 3. Descriptive statistics, factor loading, and communality for each Food Addiction criterion.

\begin{tabular}{cccc}
\hline FA criteria & $M(S D)$ & Factor loadings & Communalities \\
Tolerance & $0.36(0.48)$ & .56 & .32 \\
Withdrawal symptoms & $0.21(0.41)$ & .81 & .66 \\
$\begin{array}{c}\text { Substance taken in larger amounts and for } \\
\text { longer periods than intended }\end{array}$ & $0.25(0.44)$ & .81 & .66 \\
$\begin{array}{c}\text { Persistent desire or repeated unsuccessful } \\
\text { attempts to quit }\end{array}$ & $0.97(0.16)$ & ----- & .69 \\
$\begin{array}{c}\text { Much time/activity to obtain, use, recover } \\
\text { Important social, occupational, or recreational } \\
\text { activities given up or reduced }\end{array}$ & $0.29(0.45)$ & .83 & .51 \\
$\begin{array}{c}\text { Use continues despite knowledge of adverse } \\
\text { consequences }\end{array}$ & $0.08(0.28)$ & .71 & .26 \\
$\begin{array}{c}\text { Use causes clinically significant impairment } \\
\text { or distress }\end{array}$ & $0.21(0.41)$ & .81 & .65
\end{tabular}


Table 4. Descriptive statistics as well as correlation coefficients of the association between Yale Food Addiction Scale scores (symptom count and diagnosis scoring options) and scores on various questionnaires.

\begin{tabular}{cccc}
\hline & $M(S D)$ & \multicolumn{2}{c}{$r$} \\
\hline BES & & YFAS_S & YFAS_D \\
FCQ-T & $13.09(7.60)$ & $.65^{* * *}$ & $.51^{* * *}$ \\
BIS-Brief & $105.86(35.62)$ & $.62^{* * *}$ & $.45^{* * *}$ \\
SPQ_A & $14.17(3.50)$ & $.24^{* *}$ & .13 \\
SPQ_D & $5.36(8.01)$ & -.02 & -.00 \\
EDE_R & $1.36(4.20)$ & -.11 & -.14 \\
\hline
\end{tabular}

Note. YFAS_S_-Yale Food Addiction Scale symptom count scoring option; YFAS_D_Yale Food Addiction Scale diagnosis scoring option; BES-Binge Eating Scale; FCQ-T-Food Craving Questionnaire-Trait; BISB-Barratt Impulsiveness Scale-Brief; SPQ_A-Shorter PROMIS Questionnaire alcohol subscale; SPQ D-Shorter PROMIS Questionnaire drug subscale; EDE_R_Eating Disorder Examination restraint subscale. ${ }^{*} p<.05 ;{ }^{* *} p<.01 ;{ }^{* * *} p<.001$.

cross-cultural adaptations could account for this result (Beaton et al., 2000; Osborne \& Fitzpatrick, 2012). In addition, some items were identified as problematic in the midst of analyses. Similar results regarding problematic items were previously reported among clinical samples. For instance, low factor loadings for items 22, 24, and 25 were observed in a sample of bariatric candidates (Meule, Heckel, \& Kubler, 2012), low factor loadings for items 10 and 11, as well as items 22,24 , and 25 were observed in a sample of individuals seeking weight-loss treatment (Innamorati et al., 2015), and low factor loadings for items 19, as well as items 22,24 , and 25 were observed in a sample of patients with obesity from a primary care clinic (Nantha et al., 2016). These results are different than those obtained in samples of students (Gearhardt et al., 2009), individuals from the general population (Brunault et al., 2014; Torres et al., 2017), or individuals with lower BMI presenting eating disorders (Granero et al., 2014), where only item 24 was problematic. As put forward by Osborne \& Fitzpatrick (2012), results from exploratory factor analyses are particularly difficult to replicate and to generalize from one sample to the other, as the factor structure obtained is somewhat dependent on the sample within which the instrument is used. This could help explaining why similar results are obtained when the factor structure of the YFAS is investigated among samples presenting similar mean BMI, but behave differently when comparing different samples. In sum, the removal of problematic items when clinical samples are involved could lead to a more accurate identification of individuals suffering from FA.

A closer look at the specific problematic items revealed that almost all items associated with the criterion "Persistent desire or repeated unsuccessful attempts to quit" were identified as problematic. This criterion, which was endorsed by a high percentage of participants in the present study (97\%), was also vastly endorsed in other studies conducted among individuals suffering from obesity, for 
example at 95\% (Meule, Heckel, \& Kubler, 2012), 91\% (Innamorati et al., 2015), and 94\% (Nantha et al., 2016). These high percentages of endorsement demonstrate that this criterion cannot discriminate individuals suffering from obesity who present FA from those who do not, but rather reflect the fact that dieting and weight cycling are common in samples afflicted with weight problems. The fact that items 22 and 24 are assessed on a yes or no basis ("I want to cut down or stop eating certain kinds of food" and "I have been successful at cutting down or not eating these kinds of food") certainly contributes to the high endorsement of the criterion "Persistent desire or repeated unsuccessful attempts to quit", as individuals suffering from severe obesity may have at least once tried to cut down eating certain kinds of food and may have at least once been unsuccessful in doing so. Yet, many instruments assessing dependency and from which the YFAS was inspired (for example, the Exercise Dependence Scale-21; Hausenblas \& Downs, 2002) refer to a continuous severity scale for measuring attempts to quit. It would therefore be relevant to modify these dichotomous items when the YFAS is administered to clinical samples, in order to get closer to the reality of those encountering more severe weight and eating difficulties. Also problematic, items 10 and 11 refer to the criterion "Important social, occupational, or recreational activities given up or reduced", which was poorly endorsed in the present sample (8\%). Items reflecting the tendency to withdraw from activities may not be specific enough when it comes to individuals awaiting bariatric surgery. It is also plausible that individuals suffering from severe obesity may have already withdrawn from various activities, thus keeping their everyday lives to basic endeavors (for instance, working and taking care of the kids), or may have learned to live with their condition to a point where they no longer base their daily decisions on their eating and weight difficulties (for example, item 10 "There have been times when I avoided professional or social situations where certain foods were available, because I was afraid I would overeat" was endorsed by $1 \%$ of the participants). In order to capture a complete picture of FA, the concerns raised by the aforementioned findings will have to be taken into account when the YFAS as well as updated versions of the instrument are used among individuals suffering from severe obesity.

Regarding convergent validity, results showed that FA was strongly associated with binge eating and food cravings, which is consistent with our hypotheses and findings from the FA literature. Results related to divergent validity did not however fully correspond to our hypotheses. More specifically, the relationship between FA diagnosis and impulsivity was found to be mild but non-significant. While the number of FA criteria has been linked with impulsivity in different ways (Murphy, Stojek, \& MacKillop, 2013; Pivarunas \& Conner, 2015), the link between FA diagnosis and impulsivity is not as clear as various facets of impulsivity do not consistently differ between individuals with and without a FA diagnosis (Meule et al., 2014; Davis et al., 2011). Moreover, the relationship between the number of FA symptoms and restraint was found to be mild and sig- 
nificant. Depending on the severity level of their FA symptomatology, bariatric candidates may attempt to gain control over their problematic eating behaviors in the context of their upcoming surgery, thus relying on cognitive and dietary restraint.

The aforementioned results are to be interpreted in light of some limitations. First, the sample was considerably homogenous. Although representative of the Quebec City population, it would be interesting to extend data collection to a wider range of individuals in order to ensure generalization of the present results. Second, the sample size was relatively small. Even though it respects the guidelines provided by various authors (Guadagnoli \& Velicer, 1988; Streiner, 1994), the fact that larger sample sizes increase the stability and decrease the variability of factor loadings across samples remains important to consider (MacCallum, Widaman, Zhang, \& Hong, 1999). Lastly, participants were recruited at their preoperative visit approximately three months prior to the bariatric surgery. Participants may have already made changes in their eating habits with the help of a dietician and/or may have answered in a socially desirable manner, even though they were informed that their answers to the questionnaires would remain confidential and would not jeopardize their eligibility for the surgery. Future experiments would benefit from testing participants earlier in the process leading to the bariatric surgery.

\section{Conclusion}

Based on the data from the present study, it is possible to conclude that the French version of the YFAS could be well suited for use in a French-speaking clinical sample, following the removal or modification of problematic items. Indeed, six items included in the original YFAS (\#4, \#10, \#11, \#12, \#22, and \#24) did not appear to be appropriate when used among individuals suffering from severe weight difficulties. Attending to these problematic items will be crucial when using the YFAS and its ulterior versions to screen for possible FA among bariatric candidates. This study has important implications, as it is the first to validate the French version of the YFAS in a clinical sample and to explore the concept of FA in a subset of the French-Canadian population. It is hoped that it will facilitate further investigation of this relatively new concept by setting the necessary basis for future research and will pave the way for a deeper understanding of FA in the bariatric context.

\section{Acknowledgements}

We thank Dr. Paul Brunault and Dr. Ashley Gearhardt for giving us the authorisation to validate the French version of the YFAS in a clinical sample. We thank the Research Chair in Bariatric and Metabolic Surgery of the Quebec Heart and Lung Institute, especially Marc Lapointe and Mélanie Nadeau, and the whole surgery team for their assistance in data collection. We thank Hélène Paradis for assisting with data analysis. 


\section{References}

American Psychiatric Association (2000). Diagnostic and Statistical Manual of Mental Disorders Fourth Edition Text Revision (DSM-IV-TR). Washington DC: American Psychiatric Association. https://doi.org/10.1176/appi.books.9780890423349

Barratt, E. S. (1959). Anxiety and Impulsiveness Related to Psychomotor Efficiency. Perceptual and Motor Skills, 9, 191-198. https://doi.org/10.2466/pms.1959.9.3.191

Beaton, D. E., Bombardier, C., Guillemin, F., \& Ferraz, M. B. (2000). Guidelines for the Process of Cross-Cultural Adaptation of Self-Report Measures. SPINE, 25, 3186-3191. https://doi.org/10.1097/00007632-200012150-00014

Brunault, P., Ballon, N., Gaillard, P., Réveillère, C., \& Courtois, R. (2014). Validation of the French Version of the Yale Food Addiction Scale: An Examination of Its Factor Structure, Reliability, and Construct Validity in a Nonclinical Sample. The Canadian Journal of Psychiatry, 59, 276-284. https://doi.org/10.1177/070674371405900507

Cattell, R. B. (1966). The Scree Test for the Number of Factors. Multivariate Behavioral Research, 1, 245-276. https://doi.org/10.1207/s15327906mbr0102_10

Cepeda-Benito, A., Gleaves, D. H., Williams, T. L., \& Erath, S. A. (2000). The Development and Validation of the State and Trait Food-Cravings Questionnaires. Behavior Theray, 31, 151-173. https://doi.org/10.1016/S0005-7894(00)80009-X

Chen, G., Tang, Z., Guo, G., Liu, X., \& Xiao, S. (2015). The Chinese Version of the Yale Food Addiction Scale: An Examination of Its Validation in a Sample of Female Adolescents. Eating Behaviors, 18, 97-102. https://doi.org/10.1016/j.eatbeh.2015.05.002

Christo, G., Jones, S. L., Haylett, S., Stephenson, G. M., Lefever, R. M. H., \& Lefever, R. (2003). The Shorter PROMIS Questionnaire: Futher Validation of a Tool for Simultaneous Assessment of Multiple Addictive Behaviours. Addictive Behaviors, 28, 225-248. https://doi.org/10.1016/S0306-4603(01)00231-3

Clark, S. M., \& Saules, K. K. (2013). Validation of the Yale Food Addiction Scale among a Weight-Loss Surgery Population. Eating Behaviors, 14, 216-219. https://doi.org/10.1016/j.eatbeh.2013.01.002

Cooper, Z., \& Fairburn, C. (1987). The Eating Disorder Examination: A Semi-Structured Interview for the Assessment of the Specific Psychopathology of Eating Disorders. International Journal of Eating Disorders, 6, 1-8. https://doi.org/10.1002/1098-108X(198701)6:1<1::AID-EAT2260060102>3.0.CO;2-9

Davis, C., \& Carter, J. C. (2009). Compulsive Overeating as an Addiction Disorder. A Review of Theory and Evidence. Appetite, 53, 1-8. https://doi.org/10.1016/j.appet.2009.05.018

Davis, C., Curtis, C., Levitan, R. D., Carter, J. C., Kaplan, A. S., \& Kennedy, J. L. (2011). Evidence That "Food Addiction" Is a Valid Phenotype of Obesity. Appetite, 57, 711-717. https://doi.org/10.1016/j.appet.2011.08.017

Gearhardt, A. N., Corbin, W. R., \& Brownell, K. D. (2009). Preliminary Validation of the Yale Food Addiction Scale. Appetite, 52, 430-436. https://doi.org/10.1016/j.appet.2008.12.003

Gearhardt, A. N., White, M. A., Masheb, R. M., \& Grilo, C. M. (2013). An Examination of Food Addiction in a Racially Diverse Sample of Obese Patients with Binge Eating Disorder in Primary Care Settings. Comprehensive Psychiatry, 54, 500-505. https://doi.org/10.1016/j.comppsych.2012.12.009

Gearhardt, A. N., White, M. A., Masheb, R. M., Morgan, P. T., Crosby, R. D., \& Grilo, C. M. (2012). An Examination of the Food Addiction Construct in Obese Patients with Binge Eating Disorder. International Journal of Eating Disorders, 45, 657-663. 
https://doi.org/10.1002/eat.20957

Gormally, J., Black, S., Daston, S., \& Rardin, D. (1982). The Assessment of Binge Eating Severity among Obese Persons. Addictive Behaviors, 7, 47-55. https://doi.org/10.1016/0306-4603(82)90024-7

Granero, R., Hilker, I., Aguera, Z., Jimenez-Murcia, S., Sauchelli, S., Islam, M. A. et al. (2014). Food Addiction in a Spanish Sample of Eating Disorders: DSM-5 Diagnostic Subtype Differentiation and Validation Data. European Eating Disorders Review, 22, 389-396. https://doi.org/10.1002/erv.2311

Guadagnoli, E., \& Velicer, W. F. (1988). Relation of Sample Size to the Stability of Component Patterns. Psychological Bulletin, 103, 265-275. https://doi.org/10.1037/0033-2909.103.2.265

Hausenblas, H. A., \& Downs, D. S. (2002). How Much Is Too Much? The Development and Validation of the Exercise Dependence Scale. Psychology and Health, 17, 387-404. https://doi.org/10.1080/0887044022000004894

Innamorati, M., Imperatori, C., Manzoni, G. M., Lamis, D. A., Castelnuovo, G., Tamburello, A. et al. (2015). Psychometric Properties of the Italian Yale Food Addiction Scale in Overweight and Obese Patients. Eating and Weight Disorders, 20, 119-127. https://doi.org/10.1007/s40519-014-0142-3

MacCallum, R. C., Widaman, K. F., Zhang, S., \& Hong, S. (1999). Sample Size in Factor Analysis. Psychological Methods, 4, 84-99. https://doi.org/10.1037/1082-989X.4.1.84

Meule, A., \& Gearhardt, A. N. (2014). Five Years of the Yale Food Addiction Scale: Taking Stock and Moving Forward. Current Addiction Reports, 1, 193-215.

https://doi.org/10.1007/s40429-014-0021-Z

Meule, A., Heckel, D., \& Kübler, A. (2012). Factor Structure and Item Analysis of the Yale Food Addiction Scale in Obese Candidates for Bariatric Surgery. European Eating Disorders Review, 20, 419-422. https://doi.org/10.1002/erv.2189

Meule, A., Heckel, D., Jurowich, C. F., Vogele, C., \& Kubler, A. (2014). Correlates of Food Addiction in Obese Individuals Seeking Bariatric Surgery. Clinical Obesity, 4, 228-236. https://doi.org/10.1111/cob.12065

Meule, A., Vögele, C., \& Kübler, A. (2012). German Translation and Validation of the Yale Food Addiction Scale. Diagnostica, 58, 115-126. https://doi.org/10.1026/0012-1924/a000047

Murphy, C. M., Stojek, M. K., \& MacKillop, J. (2013). Interrelationships among Impulsive Personality Traits, Food Addiction and Body Mass Index. Appetite, 73, 45-50. https://doi.org/10.1016/j.appet.2013.10.008

Nantha, Y. S., Patah, N. A. A., \& Pillai, M. P. (2016). Preliminary Validation of the Malay Yale Food Addiction Scale: Factor Structure and Item Analysis in an Obese Population. Clinical Nutrition ESPEN, 16, 42-47.

Osborne, J. W., \& Fitzpatrick, D. C. (2012). Replication Analysis in Exploratory Factor Analysis: What It Is and Why It Makes Your Analysis Better. Practical Assessment, Research, \& Evaluation, 17, 1-8. http://pareonline.net/getvn.asp?v=17\&n=15

Pivarunas, B., \& Conner, B. T. (2015). Impulsivity and Emotion Dysregulation as Predictors of Food Addiction. Eating Behaviors, 19, 9-14. https://doi.org/10.1016/j.eatbeh.2015.06.007

Steinberg, L., Sharp, C., Stanford, M. S., \& Tharp, A. T. (2013). New Tricks for an Old Measure: The Development of the Barratt Impulsiveness Scale-Brief (BIS-Brief). Psychological Assessment, 25, 216-226. https://doi.org/10.1037/a0030550

Streiner, D. L. (1994). Figuring Out Factors: The Use and Misuse of Factor Analysis. Ca- 
nadian Journal of Psychiatry, 39, 135-140.

https://doi.org/10.1177/070674379403900303

Torres, S., Camacho, M., Costa, P., Ribeiro, G., Santos, O., Vieira, F. M. et al. (2017). Psychometric Properties of the Portuguese Version of the Yale Food Addiction Scale. Eating and Weight Disorders, 22, 259-267. https://doi.org/10.1007/s40519-016-0349-6

World Health Organization (2017). Obesity and Overweight. Fact Sheet 311. http://www.who.int/mediacentre/factsheets/fs311/en/

Zumbo, B. D., Gadermann, A. M., \& Zeisser, C. (2007). Ordinal Versions of Coefficients Alpha and Theta for Likert Rating Scales. Journal of Modern Applied Statistical Methods, 6, 21-29. https://doi.org/10.22237/jmasm/1177992180 